\title{
Investigation of Activated Carbon/Ethanol for Low Temperature Adsorption Cooling
}

\author{
Elsayed, A. , Al-Dadah, R. K. , Mahmoud, S. and Kaialy, W.
}

Author post-print (accepted) deposited by Coventry University's Repository

Original citation \& hyperlink:

Elsayed, A. , Al-Dadah, R. K. , Mahmoud, S. and Kaialy, W. (2015) Investigation of Activated Carbon/Ethanol for Low Temperature Adsorption Cooling. International Journal of Green Energy, volume (In Press)

http://dx.doi.org/10.1080/15435075.2014.937867

DOI $\quad 10.1080 / 15435075.2014 .937867$

ISSN 1543-5075

ESSN $1543-5083$

Publisher: Taylor and Francis

This is an Accepted Manuscript of an article published by Taylor \& Francis in International Journal of Green Energy on $14^{\text {th }}$ December 2015 , available online: http://www.tandfonline.com/10.1080/15435075.2014.937867

Copyright $(\odot$ and Moral Rights are retained by the author(s) and/ or other copyright owners. A copy can be downloaded for personal non-commercial research or study, without prior permission or charge. This item cannot be reproduced or quoted extensively from without first obtaining permission in writing from the copyright holder(s). The content must not be changed in any way or sold commercially in any format or medium without the formal permission of the copyright holders.

This document is the author's post-print version, incorporating any revisions agreed during the peer-review process. Some differences between the published version and this version may remain and you are advised to consult the published version if you wish to cite from it. 
Internationa

\section{Investigation of Activated Carbon/Ethanol for Low Temperature Adsorption Cooling}

\section{Ahmed Elsayed, Raya K. AL-Dadah, Saad Mahmoud \& Waseem Kaialy}

To cite this article: Ahmed Elsayed, Raya K. AL-Dadah, Saad Mahmoud \& Waseem Kaialy (2015): Investigation of Activated Carbon/Ethanol for Low Temperature Adsorption Cooling, International Journal of Green Energy, DOI: 10.1080/15435075.2014.937867

To link to this article: http://dx.doi.org/10.1080/15435075.2014.937867

Accepted author version posted online: 14

Dec 2015.

Submit your article to this journal

View related articles ¿

View Crossmark data \lceil 


\title{
Investigation of Activated Carbon / Ethanol for Low Temperature Adsorption Cooling
}

\author{
Ahmed Elsayed $^{1,2}$, Raya K. AL-Dadah ${ }^{1, *}$, Saad Mahmoud ${ }^{1}$, Waseem Kaialy ${ }^{3}$ \\ ${ }^{1}$ School of Mechanical Engineering \\ University of Birmingham, United Kingdom, B15-2TT. \\ ${ }^{2}$ University of Alexandria, Mechanical Engineering Department \\ ${ }^{3}$ Chemistry and Drug Delivery Group, Medway School of Pharmacy, University of Kent, ME4 \\ 4TB, Kent, UK
}

\begin{abstract}
Commercially available adsorption cooling systems use water/silica gel, water/zeolite and ammonia/ chloride salts working pairs. The water based pairs are limited to work above $0{ }^{\circ} \mathrm{C}$ due to the water high freezing temperature, while ammonia has the disadvantage of being toxic. Ethanol is a promising refrigerant due to its low freezing point (161 K), non-toxicity, zero ozone depletion and low global warming potential. Activated carbon (AC) is a porous material with high degree of porosity (500-3000 $\left.\mathrm{m}^{2} / \mathrm{g}\right)$ that has been used in wide range of applications. Using Dynamic Vapour Sorption (DVS) test facility, this work characterizes the ethanol adsorption of eleven commercially available activated carbon materials for cooling at low temperature of $15^{\circ} \mathrm{C}$. DVS adsorption results show that Maxsorb has the best performance in terms of ethanol uptake and adsorption kinetics compared to the other tested materials. The Maxsorb/ethanol adsorption process has been numerically modeled using computational fluid dynamics (CFD) and simulation results are validated using the DVS experimental measurements. The validated CFD simulation of the adsorption process is used to predict the effects of adsorbent layer
\end{abstract}


thickness and packing density on cycle uptake for evaporating temperature of $-15^{\circ} \mathrm{C}$. Simulation results show that as the thickness of the Maxsorb adsorbent layer increases, its uptake decreases. As for the packing density, the amount of ethanol adsorbed per plate increases with the packing density reaching maximum at $750 \mathrm{~kg} / \mathrm{m}^{3}$. This work shows the potential of using Maxsorb/ethanol in producing low temperature cooling down to $-15^{\circ} \mathrm{C}$ with specific cooling energy reaching $400 \mathrm{~kJ} / \mathrm{kg}$.

Keywords: adsorption cooling, activated carbons/ethanol, computational fluid dynamics (CFD), low temperature refrigeration.

\section{INTRODUCTION}

Commercial adsorption cooling systems are now produced by a limited number of manufacturing companies in Japan (Nishyodo, Mayekawa), USA (Eco-Max), UK (Weatherite), and Germany (Sortech, Invensor, Zeotech) as reviewed by Henning (2010); however, most of these cooling units utilize water as a refrigerant, which limits their minimum operating temperature to be above zero. A number of industrial applications require low temperature cooling (below zero) like medical use (Aslam et al. 2009) and food industry (Ammar et al. 2012). Commercially available low temperature adsorption systems use chemical sorption technique with ammonia as the refrigerant and various salts as adsorbents (Fan et al. 2007). Such systems suffer from the toxic effect of ammonia and the corrosiveness of the salts used. Therefore, there is a need to investigate more effective adsorption pairs for low temperature cooling. Ethanol has been reported as a promising refrigerant due to its low freezing point, , high chemical stability, non- 
toxicity, zero ozone depletion, low global warming potential (Ketteringham et al. 2012; Tiansuwan and Hirunlabh 1998; El-Sharkawy et al. 2008) and low cost for commercial manufacture.

Activated carbons have large surface area and exhibit good affinity towards ethanol. Aslam et al. (2009) developed a refrigerator for vaccine preservation with coconut shell activated carbon/ethanol pair; the tested refrigerator achieved evaporating temperature of $3.3{ }^{\circ} \mathrm{C}$. ElSharkawy et al. (2008) measured the adsorption isotherms for activated carbon Maxsorb III and investigated its use with ethanol for evaporating temperatures of $7{ }^{\circ} \mathrm{C}$ and predicted a cycle COP of 0.8 , the authors concluded that Maxsorb is suitable for solar cooling systems.

Loh et al. (2009) utilized equilibrium cycle analysis for evaluating the performance of activated carbon fibers $\mathrm{ACF}(\mathrm{A}-15)$ and $\mathrm{ACF}(\mathrm{A}-20)$ with ethanol at $6.7^{\circ} \mathrm{C}$ evaporating temperature. $\mathrm{ACF}$ (A-20) showed the highest cooling effect among the tested pairs (up to $345 \mathrm{~kJ} / \mathrm{kg}_{\text {ads }}$ for single stage cycles and up to $230 \mathrm{~kJ} / \mathrm{kg}_{\text {ads }}$ for two-stage adsorption cycle but it offers the ability to utilize low temperature heat sources). Mugnier and Goetz (2001) made a theoretical thermodynamic analysis for Maxsorb activated carbon (PX21) with different refrigerants including ethanol, ammonia and $\mathrm{SO}_{2}$. Ethanol/Maxsorb showed the highest specific cooling capacity of $50 \mathrm{Wh} / \mathrm{kg}_{\text {ads }}\left(180 \mathrm{~kJ} / \mathrm{kg}_{\text {ads }}\right)$. Saha et al. (2007a, 2007b) developed a simulation model for 2-bed adsorption chiller using ethanol and $\operatorname{ACF}(\mathrm{A}-20)$ using low temperature heat source between $60{ }^{\circ} \mathrm{C}$ to $95{ }^{\circ} \mathrm{C}$ and adsorption/desorption time of 600 sec with 30 sec switching between the beds. They showed that ethanol/ACF(A-20) produced higher COP (0.6) compared to that of silica gel/water pair (0.45). Tiansuwan (1997) tested three samples of activated carbon 
with different particle size namely; 1, 2-3 and $5 \mathrm{~mm}$. The activated carbon with 2-3mm particle size showed the highest ethanol uptake and achieved an evaporating temperature of $5{ }^{\circ} \mathrm{C}$ when tested in an adsorption cooling system. El-Sharkawy et al. (2006) studied experimentally and numerically the kinetics of activated carbon fiber ACF A-20 with ethanol and developed a new form of linear driving force (LDF) for cylindrical adsorbent that could capture the higher ethanol uptake in ACF.

Zheng and Gu (2006) presented a thermodynamic model for a rotary adsorber for continuous operation using activated carbon fibre and ethanol. They concluded that this pair can achieve a cooling system with many advantages including a simple structure, fast refrigeration and higher thermodynamic coefficient of performance. Yurtsever (2011) tested ethanol, acetone, and npentane with activated carbon pellets with $2 \mathrm{~mm}$ diameter and 2-4 mm length using a gravimetric analyzer for heat pump application. Although the three fluids are non-toxic, ethanol showed better performance compared to the other two fluids.

The above published work showed the potential of activated carbon / ethanol for adsorption cooling systems with evaporating temperatures above zero (ranging from $3^{\circ} \mathrm{C}$ to $7^{\circ} \mathrm{C}$ ). This work investigates the feasibility of using activated carbon materials / ethanol to achieve low temperature cooling at $-15^{\circ} \mathrm{C}$. The ethanol adsorption characteristics of eleven commercially available activated carbon materials (shown in table 1) were measured using Dynamic Vapor Sorption (DVS) test facility and the best performing material (Maxsorb) was modelled using computational fluid dynamics techniques (CFD). The CFD modeling of the adsorption process was then used to predict the effects of adsorbent thickness and packing density on cycle uptake 
for evaporating temperature of $-15^{\circ} \mathrm{C}$. Equilibrium cycle analysis at low evaporating temperature of $-15^{\circ} \mathrm{C}$ of various refrigerants / activated carbon pairs was also conducted.

\section{EXPERIMENTAL CHARACTERISATION OF}

\section{ACTIVATED CARBON ADSORBENT MATERIALS}

This section describes the experimental facilities used to measure the adsorption characteristics of various activated carbon materials and the technique used to measure the particle size. A Sympatec HELOS/RODOS (Clausthal-Zellerfeld, Germany) laser diffraction-particle size analyser was used to determine the volume-weighted particle size of different samples, as adopted from (Kaialy et al. 2011). Moisture content of the samples was determined by the Karl Fisher method (Metter Toledo, C20 Coulometric KF Titrator, Switzerland). The Fischer reagent solution was Hydranal ${ }^{\circledR}$ Coulomat AF (Sigma Aldrich, USA). The titration of each sample was repeated three times and an average value was taken as given in Table 1 . The size and morphology of all samples were examined using a field emission scanning electron microscopy (SEM, HITACHI SU 8030, Japan) as described in (Kaialy et al. 2013). Samples were mounted

on adhesive carbon tabs (G3347N, Agar Scientific, England) which were in turn mounted onto aluminium pin stubs (G301, Agar Scientific, England). Figure 1 shows the SEM images of the 11 activated carbon materials tested indicating that Maxsorb powder has the largest particles across the powders tested with a mean diameter of $65.6 \pm 1.3 \mu \mathrm{m}$. NORIT RX1 and RX2 products were shown as large pellets having wrinkled (rough) porous surface. 
For measuring the adsorption characteristics (adsorption isotherms, kinetics and isosters), a dynamic vapour sorption (DVS) gravimetric analyser shown schematically in figure 2 has been used. In this DVS analyser, the adsorbent mass is measured directly using sensitive recording microbalance (Cahn D200) as the material adsorbs controlled concentrations of ethanol. Dry Nitrogen is used to purge the balance head and reaction chamber prior to sample loading. The purge flow is automatically controlled to prevent vapour condensation in the balance head and hence accurate uptake measurement is guaranteed. The microbalance is housed in a controlled temperature chamber to avoid vapour condensation in connections. Mass flow controller is used to control the vapour pressure with a mixture of Nitrogen and ethanol vapour. The uptake was defined as the ratio of the difference between temporal mass measured and mass of adsorbent after drying process (before starting of adsorption) divided by the mass of adsorbent after drying process. The test conditions were measured using optical vapour pressure sensor and RTD temperature probe very close to sample pan. The DVS analyser is controlled by a PC microcomputer, which is interfaced with the microbalance. The mass measurement accuracy of the tested samples (10 mg initially loaded) is $\pm 0.05 \mathrm{mg}$. The samples were first dried at $150{ }^{\circ} \mathrm{C}$ then adsorption process was carried out at temperatures of 15 and $25^{\circ} \mathrm{C}$.

Figure 3 shows the measured ethanol uptake for the various activated carbon materials tested, where Figure 3a shows the ethanol uptake variation with time at a partial pressure ratio of $5 \%$. The $5 \%$ partial pressure is equivalent to the ratio of ethanol vapour pressure corresponding to evaporating temperature of $-15{ }^{\circ} \mathrm{C}$ to the ethanol vapour pressure corresponding to adsorber bed temperature of $25^{\circ} \mathrm{C}$. Figure 3a shows that Maxsorb has the highest uptake with favourable kinetics compared to the other adsorbents. During experimental measurements, data was 
collected for partial pressure ratios (P/Ps) ranging from 5\% to 90\% to generate the adsorption isotherms. Figure 3b compares the maximum ethanol uptake obtained at steady state conditions and the time required to reach such steady state for partial pressure ratio of $90 \%$. It is clear from figure 3b that Maxsorb has the maximum uptake value of $1.18 \mathrm{~kg} / \mathrm{kg}_{\text {ads }}$ at a steady state time of 500 mins followed by HDLC and SRD12005. ATO, SRD12006 and RX1 have similar performance. This performance of Maxsorb can be attributed to its large surface area of 3000 $\mathrm{m}^{2} / \mathrm{g}$ compared to other materials as shown in table 1 .

The experimental measurements shown in figure 3 have been used to develop mathematical correlations to predict the ethanol uptake of the adsorption materials at various operating conditions. The linear driving force (LDF) model is used for simulating the adsorption kinetics of different pairs as given by equation 1 (Saha et al. 2007a):

$$
x / x_{\text {eq }}=1-\exp \left(-k_{L D F} t\right)
$$

$x, x_{e q}$ are the temporal and equilibrium uptake considering surface diffusion and $k_{L D F}$ is the mass transfer coefficient. Using the measured data at two different temperatures, the activation energy ( $E_{a}$, equation 2) and the temperature dependent diffusion rate constant $\left(k_{o}\right.$, equation 3) can be determined using Arrhenius formula. 


$$
\begin{aligned}
& E_{a}=R \ln \left(\frac{k_{L D F, 2}}{k_{L D F, 1}}\right) /\left(\frac{1}{T_{1}}-\frac{1}{T_{2}}\right) \\
& \\
& k_{o}=k_{L D F} / \exp \left(\frac{-E_{a}}{R T}\right)
\end{aligned}
$$

Figure 4a shows the measured and predicted kinetics of Maxsorb materials at $15^{\circ} \mathrm{C}$ and $25^{\circ} \mathrm{C}$ compared to the predicted kinetics using the LDF model. It is clear from figure 4a, that decreasing the bed temperature increases the maximum adsorption capacity. However, decreasing the bed temperature requires a longer time for the samples to reach its full capacity. This may be explained as follows: as the bed temperature decreases, the operating pressure decreases for the same partial pressure ratio, and the pressure difference reduces which results in longer time for the vapour to penetrate through the pores.

For adsorption isotherms, many mathematical models were reported by various researchers such as Dubinin-Astakhov (D-A), Sips, Tóth, Freundlich, Langmuir, Temkin and Hill-de Boer (Rezk et al. 2013). The profile of the measured isotherm determines the type of model that can be used. The adsorption isotherms for the activated carbon adsorbents were found to fit the DubininAstakhov model shown in equation 4 (El-Sharkawy et al. 2008; Rezk et al. 2013).

$$
x_{e q}=x_{\max } \exp \left(-\left(\frac{A}{E}\right)^{m}\right)
$$

where

$$
A=-R T 1 n\left(\frac{P}{P_{S}}\right)
$$


$\mathrm{x}_{\max }, E$ and $m$ are empirical parameters that were determined by fitting the uptake with Polanyi potential $(A)$. Figure 4b shows the measured isotherms of maxsorb compared to the predicted isotherms. Table 2 summarizes the different constants generated from fitting the experimental data to kinetics and isotherms models (equations 1 and 4). The mathematical correlations developed through equations 1-5 are required to carry out the CFD modelling for investigating the effects of adsorbent layer thickness and its packing density on ethanol adsorption characteristics.

\section{CFD MODELLING OF ADSORPTION PROCESS}

Computational Fluid Dynamic (CFD) modelling is powerful tool for simulating heat and mass transfer in adsorption systems. This section describes the CFD model setup for a flat plate bed packed from one side with activated carbon and the cooling water flows on the other side of the plate (shown schematically in figure 5), its governing equations and validation. The mass, momentum and energy balance in the porous bed are expressed by equations 6, 7 and 8 (Sahoo et al. 2011):

$$
\begin{aligned}
& \frac{\partial\left(\varepsilon \rho_{g}+\rho_{b} x\right)}{\partial t}+\nabla \cdot\left(\rho_{g} u_{g}\right)=0 \\
& \frac{\rho_{g}}{\varepsilon} \frac{\partial u_{g}}{\partial t}+\frac{\rho_{g}}{\varepsilon^{2}} u_{g} \cdot \nabla u_{g}=-\nabla P+\mu_{g} \nabla^{2} u_{g}-\frac{\mu_{g}}{K} u_{g} \\
& (\rho c)_{\text {eff }} \frac{\partial T}{\partial T}+\rho_{g} C_{p, g} u_{g} \cdot \nabla T=\nabla \cdot\left(\lambda_{\text {eff }} \nabla T\right)+\rho_{b} \Delta H \frac{\partial x}{\partial t}
\end{aligned}
$$


Neglecting the unsteady, drag and viscous terms; the momentum equation (7) reduces to the Darcy form as:

$$
u_{g}=-\frac{K}{\mu_{g}} \nabla P
$$

where the permeability K was calculated from:

$$
K=\frac{d_{p}^{2} \varepsilon^{3}}{150(1-\varepsilon)^{2}}
$$

$\Delta H$ in the energy equation (8) is the heat of adsorption $[\mathrm{J} / \mathrm{kg}]$ and $x$ is the uptake. The effective specific heat and thermal conductivity values were calculated using Maxwell-Eucken form as:

$$
\begin{gathered}
(\rho c)_{\text {eff }}=\left(\varepsilon \rho_{g}+\rho_{b} x\right) C_{p, g}+(1-\varepsilon) \rho_{s} C_{p, s} \\
\rho_{b}=(1-\varepsilon) \rho_{s} \\
\lambda_{\text {eff }}=\lambda \frac{2 \lambda_{s}+\lambda_{g}-2 \varepsilon\left(\lambda_{s}-\lambda_{g}\right)}{2 \lambda_{s}+\lambda_{g}+\varepsilon\left(\lambda_{s}-\lambda_{g}\right)}
\end{gathered}
$$

where $\rho_{b}$ and $\rho_{s}$ are the packing and solid carbon densities. The packing density was assumed to be $300 \mathrm{~kg} / \mathrm{m}^{3}$ (Saha et al. 2006).

The adsorption rate was calculated by differentiating equation 1 . The Darcy model was used to calculate the pressure distribution in the porous bed and k- $\varepsilon$ model was used to model the turbulent flow of water. Also, the heat transfer module was used to solve the energy equation in 
the porous bed, steel plate and water side. Table 3 summarizes the input parameters required for the CFD model. The fluid properties were obtained from the Comsol materials library for gases and liquids of ethanol and cooling water. The particle diameter used for Maxsorb activated carbon sample is $0.0656 \mathrm{~mm}$.

Figure 6 shows the variation of adsorbent uptake and temperature distribution in a $20 \mathrm{~mm}$ Maxsorb adsorbent layer at 180 sec from the start of adsorption process with sections at the center of the plates. It can be seen that the relatively high temperature of the upper part of the adsorbent layer causes less uptake of the diffused ethanol vapour compared to that at the lower part of the adsorbent where the temperature is lower. Figure 7 compares the DVS measured ethanol uptake for Maxsorb layer thickness of $1 \mathrm{~mm}$ to the CFD predicted average uptake for the same layer thickness. The deviation between the experimental results and those of the CFD is less than $8 \%$.

\section{CFD RESULTS}

Using the CFD modelling developed in section 3, this section investigates the effect of adsorbent layer thickness and packing density on the Maxsorb / ethanol uptake and the bed specific cooling power. 


\subsection{Effect of Adsorbent Layer Thickness}

The adsorbent layer thickness plays a major role in determining the overall system performance in terms of size, cooling capacity and energy efficiency. The amount of adsorbed refrigerant equals to the refrigerant uptake multiplied by the amount of adsorbent material. As the adsorbent layer thickness increases, the mass of adsorbent material increases but the refrigerant uptake decreases due to the reduction in the bed permeability and the reduction in the effectiveness of cooling the adsorbent material. With this opposing effects of the material thickness, a detailed CFD analysis was carried out to predict the effect of packing thickness on the ethanol uptake of Maxsorb and adsorber bed temperature using Comsol Multiphysics to identify the most effective packing thickness. Figure 8 shows the effect of adsorbent thickness (ranging from $1 \mathrm{~mm}$ to $20 \mathrm{~mm}$ ) on the ethanol uptake and adsorbent bed temperature for initially dry adsorbent layer $(\mathrm{x}=$ 0 ). It shows that the average ethanol uptake decreases as the adsorbent thickness increases. However, the rate of decrease in the uptake increases significantly as the layer thickness increases above $8 \mathrm{~mm}$. This can be attributed to the temperature variation shown in Figure 9 where above $8 \mathrm{~mm}$ layer thickness, the average adsorbent temperature initially (first $200 \mathrm{sec}$ ) starts to increase to a maximum value and then starts to drop monotonically. This clearly indicates that adsorbent packing thickness below $8 \mathrm{~mm}$ can be cooled effectively and hence offer better adsorption characteristics in terms of uptake per unit mass of adsorbent and offer higher cooling capacity. Such temperature behavior with adsorbent thickness have been observed by other researchers such as Füldner (2008) and Riffel et al. (2010). 
In a real chiller operation, the adsorbent material cycles between upper and lower concentration levels which are determined by the operating conditions. The initial uptake will have a defined value (calculated from eq. 4) and this will reduce the uptake change during the cycle. Figure 10 shows the variation of specific cooling power of Maxsorb with time at the layer thicknesses shown in figure 9. It is clear that using large packing thicknesses supress the specific cooling power significantly as the SCP decreases from $45 \mathrm{~W} / \mathrm{kg}$ to $14 \mathrm{~W} / \mathrm{kg}$ by increasing the packing depth from $5 \mathrm{~mm}$ to $20 \mathrm{~mm}$.

\subsection{Effect of The Bed Packing Density}

All the above CFD analysis was carried out using adsorbent packing density of $300 \mathrm{~kg} / \mathrm{m}^{3}$ as reported for Maxsorb (Saha et al. 2006). The packing density of the bed affects the mass and heat transfer performance. Increasing the packing density reduces the bed permeability, but in the same time increases the effective thermal conductivity as shown in figure 11 . Reducing the bed permeability results in reducing the diffusion of ethanol into the adsorbent material and hence reduces the uptake. However, increasing the effective thermal conductivity increases the heat transfer rate which can increase the uptake. Therefore, there is a need to determine the packing density of the bed that produces the highest amount of ethanol adsorbed. Several packing densities for Maxsorb ranging from 300 to $1500 \mathrm{~kg} / \mathrm{m}^{3}$ were used to predict the effect of packing density on the amount of ethanol adsorbed per plate as shown in Figure 12. It is clear from this figure that for all cycle times used, the total ethanol adsorbed per plate (directly affecting the cooling capacity) increases with increase of packing density until it reaches a 
maximum at a packing density of $750 \mathrm{~kg} / \mathrm{m}^{3}$. Also, Figure 12 shows that using packing densities above $750 \mathrm{~kg} / \mathrm{m}^{3}$ have no effect on the amount of ethanol adsorbed per plate.

\subsection{Comparison to Low Temperature Adsorbent/Refrigerant Pairs}

The performance of Maxsorb activated carbon/ethanol pair was compared to other activated carbon / low temperature refrigerants pairs using standard equilibrium adsorption cycle analysis with $T_{\text {evap }}=-15^{\circ} \mathrm{C}, T_{a d s}=25{ }^{\circ} \mathrm{C}, T_{\text {cond }}=30{ }^{\circ} \mathrm{C}$ and various desorption (regeneration) temperatures ranging from 90 to 120 . Figure 13 shows the comparison of Maxsorb/ ethanol with the following pairs: methanol/Fx400 (Hamamoto et al. 2006), R134a/ Ax-21 activated carbon (Askalany et al. 2012), R744/208C activated carbon (Zhong et al. 2006), and ammonia / SRD 13252-2 carbon (Tamainot-Telto et al. 2009). Figure 13a shows the refrigerant cycle uptake versus the regeneration temperature with ethanol/Maxsorb being superior compared to other adsorbent/refrigerant pairs. To take into account the effect of the refrigerant, figure 13b shows the Specific Cooling Energy (SCE) versus the regeneration temperature indicating that the best pair is Maxsorb/ethanol producing SCE ranging from 150 to $400 \mathrm{~kJ} / \mathrm{kg}_{\text {ads }}$.

\section{CONCLUSIONS}

Activated carbon / ethanol is a promising pair in adsorption cooling technology where waste heat can be used to generate low temperature cooling down to $-15^{\circ} \mathrm{C}$. In this work 11 activated carbon materials commercially available have been characterized in terms of their ethanol adsorption performance using the Dynamic Vapour Sorption (DVS) test facility. Results showed 
that Maxsorb outperforms other activated carbon materials both in terms of the maximum equilibrium uptake $1.18 \mathrm{~kg} / \mathrm{kg}_{\text {ads }}$.

Computational Fluid Dynamic technique was developed to simulate the adsorption process for Maxsorb / ethanol using DVS experimental data and the Darcy model of porous material in COMSOL multiphysics software. This modelling technique was validated against experimental measurement with deviation of less than $8 \%$.

Adsorbent layer thickness and Packing density have significant impact on the adsorption system performance in terms of size and cooling capacity. CFD simulations were used to predict the effect of those two parameters. CFD results showed that as the thickness of the Maxsorb adsorbent layer increased, its uptake decreased. As for the packing density, the amount of ethanol adsorbed per plate increased with the packing density reaching maximum at $750 \mathrm{~kg} / \mathrm{m}^{3}$.

Also, comparing ethanol/Maxsorb performance to other working pairs (reported in literature) in terms of specific cooling energy showed that ethanol/Maxsorb significantly outperform the other pairs for low temperature cooling. The outcome of this work shows the advantages of using Maxsorb activated carbon/ethanol in producing low temperature cooling down to $-15^{\circ} \mathrm{C}$ with specific cooling energy up to $400 \mathrm{~kJ} / \mathrm{kg}$.

\section{Acknowledgements}

The authors wish to thank Weatherite Holdings Ltd and the Knowledge Transfer Partnership (KTP) for sponsoring the project. Dr. Ali Nokhodchi (University of Kent) is thanked for access to laser diffraction facility. 


\section{References}

Ammar, Y., S. Joyce, R. Norman, Y. Wang, and A.P. Roskilly. 2012. Low grade thermal energy sources and uses from the process industry in the UK. Applied Energy 89: 3-20.

Askalany, A.A., M. Salem, I.M. Ismail, A.H. Ali, and M.G. Morsy. 2012. Experimental study on adsorption-desorption characteristics of granular activated carbon/R134a pair. International journal of refrigeration 35: 494-498.

Aslam, N., K. McPhail, R. McPhee, B. Rowland, and E. Tingwall. 2009. Vaccine Refrigerator for Developing Nation. Project Engineering Design.

http://apptechdesign.org/wp-content/uploads/2009/05/finalfridgereport1.pdf

El-Sharkawy, I.I., B.B. Saha, S. Koyama, and K.C. Ng. 2006. A study on the kinetics of ethanolactivated carbon fiber: Theory and experiments. International Journal of Heat and Mass Transfer 49: 3104-3110.

El-Sharkawy, I.I., B.B. Saha, S. Koyama, J. He, K.C. Ng, C. Yap. 2008. Experimental investigation on activated carbon-ethanol pair for solar powered adsorption cooling applications. International Journal Refrigeration 31(8): 1407 - 1413.

Fan, Y., L. Luo, and B. Souyri. 2007. Review of solar sorption refrigeration technologies: Development and applications. Renewable and Sustainable Energy Reviews 11:1758-1775.

Füldner, G., and L. Schnable. 2008. Non-isothermal kinetics of water adsorption in compact adsorbent layers on a metal support. Comsol conference proceeding, Hannover. http://www.comsol.com/papers/5118/ 
Hamamoto, Y., K.C.A. Alam, B.B. Saha, S. Koyama, A. Akisawa, and T. Kashiwagi. 2006. Study on adsorption refrigeration cycle utilizing activated carbon fibers. Part 1. Adsorption characteristics. International Journal of Refrigeration 29: 305-314.

Henning, H. 2010. Adsorption closed cycles and machines. Workshop solar air-conditioningDenmark.

Kaialy, W., G.P. Martin, M.D. Ticehurst, P. Royall, M.A. Mohammad, J. Murphy, A. Nokhodchi. 2011. Characterisation and deposition studies of recrystallised lactose from binary mixtures of ethanol/butanol for improved drug delivery from dry powder inhalers. AAPS Journal 13: $30-43$.

Kaialy, W., T. Hussain, A. Alhalaweh, and A. Nokhodchi. 2013. Towards a More Desirable Dry Powder Inhaler Formulation: Large Spray-Dried Mannitol Microspheres Outperform Small Microspheres. Pharmaceutical Research. In press.

Ketteringham, L., M. Tierney, M. Ahamat, H. Saidani-Scott, and R. Selwyn. 2012. Design and construction of a low cost solar chiller, with calorimetric assessment of the adsorbent bed. http://ases.conference-

services.net/resources/252/2859/pdf/SOLAR2012_0218_full\%20paper.pdf

Loh W.S., I.I. El-Sharkawy, K.C. Ng, and B.B. Saha. 2009. Adsorption cooling cycles for alternative adsorbent/adsorbate pairs working at partial vacuum and pressurized conditions. Applied Thermal Engineering 29: 793-798.

Mugnier, D., and V. Goetz. 2001. Energy storage comparison of sorption systems for cooling and refrigeration. Solar Energy 71:47-55. 
Rezk, A., R. AL-Dadah, S. Mahmoud, and A. Elsayed. 2013. Investigation of Ethanol/metal organic frameworks for low temperature adsorption cooling applications. Applied Energy 112: 1025-1031.

Riffel, D.B., U. Wittstadt, F.P. Schmidt, T. Núñez, F.A. Belo, A.P.F. Leite , and F. Ziegler. 2010. Transient Modeling of an adsorber using finned-tube heat exchanger. International Journal of Heat and Mass Transfer 53(7-8): 1473-1482.

Saha, B.B., I.I. El-Sharkawy, A. Chakraborty, S. Koyama, N.D. Banker, P. Dutta, M. Prasad, and K. Srinivasan. 2006. Evaluation of minimum desorption temperatures of thermal compressors in adsorption refrigeration cycles. International Journal of Refrigeration; 29: 1175-1181.

Saha, B.B., I.I. El-Sharkawy, A. Chakraborty, S. Koyama. 2007a. Study on an activated carbon fiber ethanol adsorption chiller: Part I - system description and modelling. International Journal Refrigeration 30: 86-95.

Saha, B.B., I.I. El-Sharkawy, A. Chakraborty, and S. Koyama. 2007b. Study on an activated carbon fiber ethanol adsorption chiller: Part II-performance evaluation. International Journal Refrigeration. 30: 96-102.

Sahoo, P. K., M. John, B.L. Newalkar, N.V. Choudhary, K.G. Ayappa. 2011. Filling Characteristics for an Activated Carbon Based Adsorbed Natural Gas Storage System. Industrial and Engineering Chemistry Research 50: 13000-13011.

Tamainot-Telto, Z., S.J. Metcalf, R.E. Critoph, Y. Zhong, and R. Thorpe. 2009. Carbonammonia pairs for adsorption refrigeration applications: ice making, air conditioning and heat pumping. International journal of refrigeration 32: $1212-1229$. 
Tiansuwan, J. 1997. Performance analyses of adsorption refrigeration system using activated carbon- ethanol as working fluid. $\mathrm{PhD}$ thesis.

Tiansuwan, J., and J. Hirunlabh. 1998. Mathematical Model of an Activated Carbon-Ethanol Refrigerator. Thammasat International Journal of Science and Technology 3:1.

Yurtsever, A.O. 2011. Mathematical modeling of adsorption/desorption systems for chemical heat pumps. Msc thesis.

Zheng, A., and J. Gu. 2006. An Advanced Solar-Powered Rotary Solid Adsorption Refrigerator with High Performance. Renewable Energy Resources and a Greener Future 8:7-3.

Zhong, Y., R.E. Critoph, and R. Thorpe. 2006. Evaluation of the performance of solid sorption refrigeration systems using carbon dioxide as refrigerant. Applied Thermal Engineering 26: $1807-1811$. 
Table 1 Tested activated carbon samples

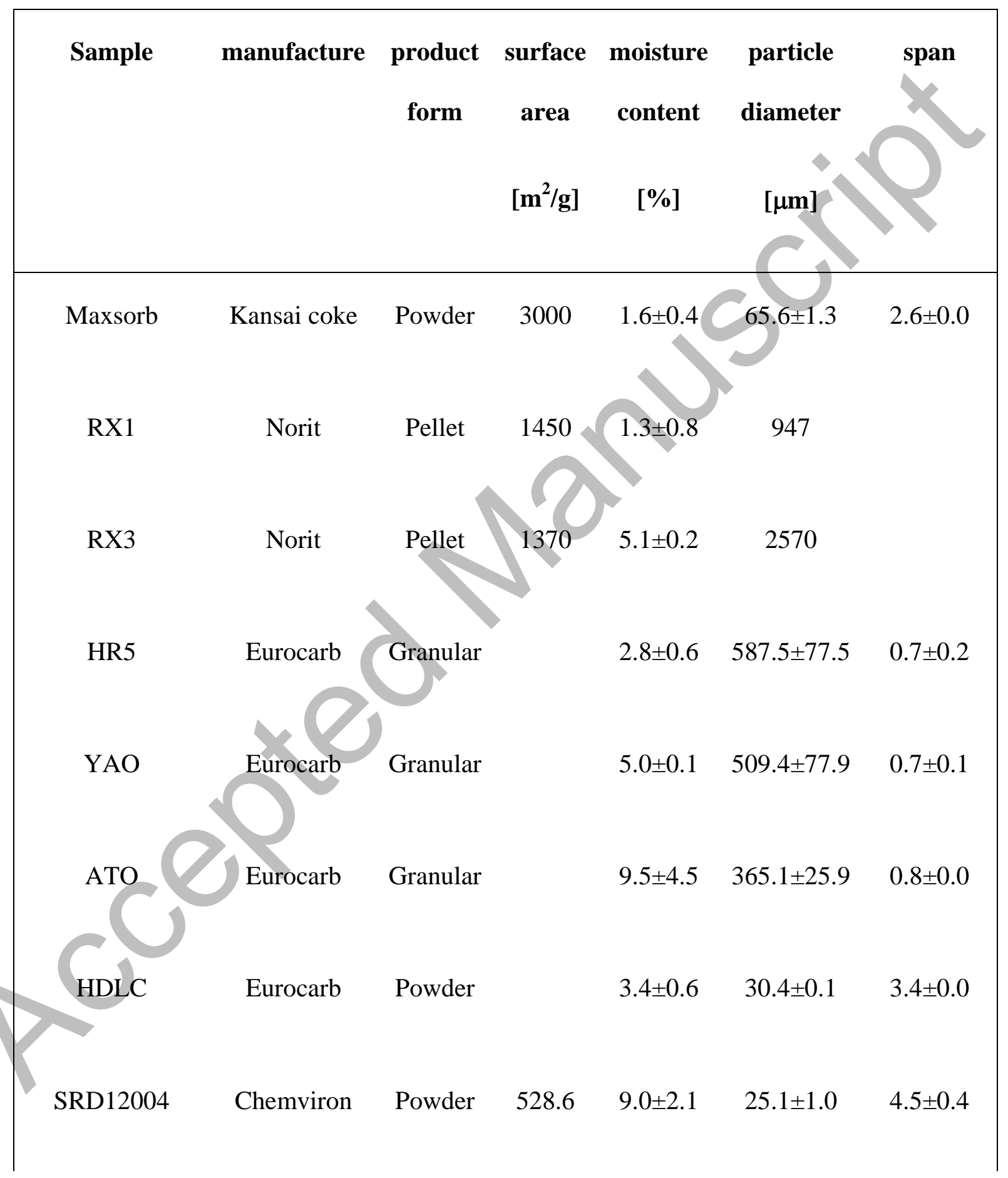




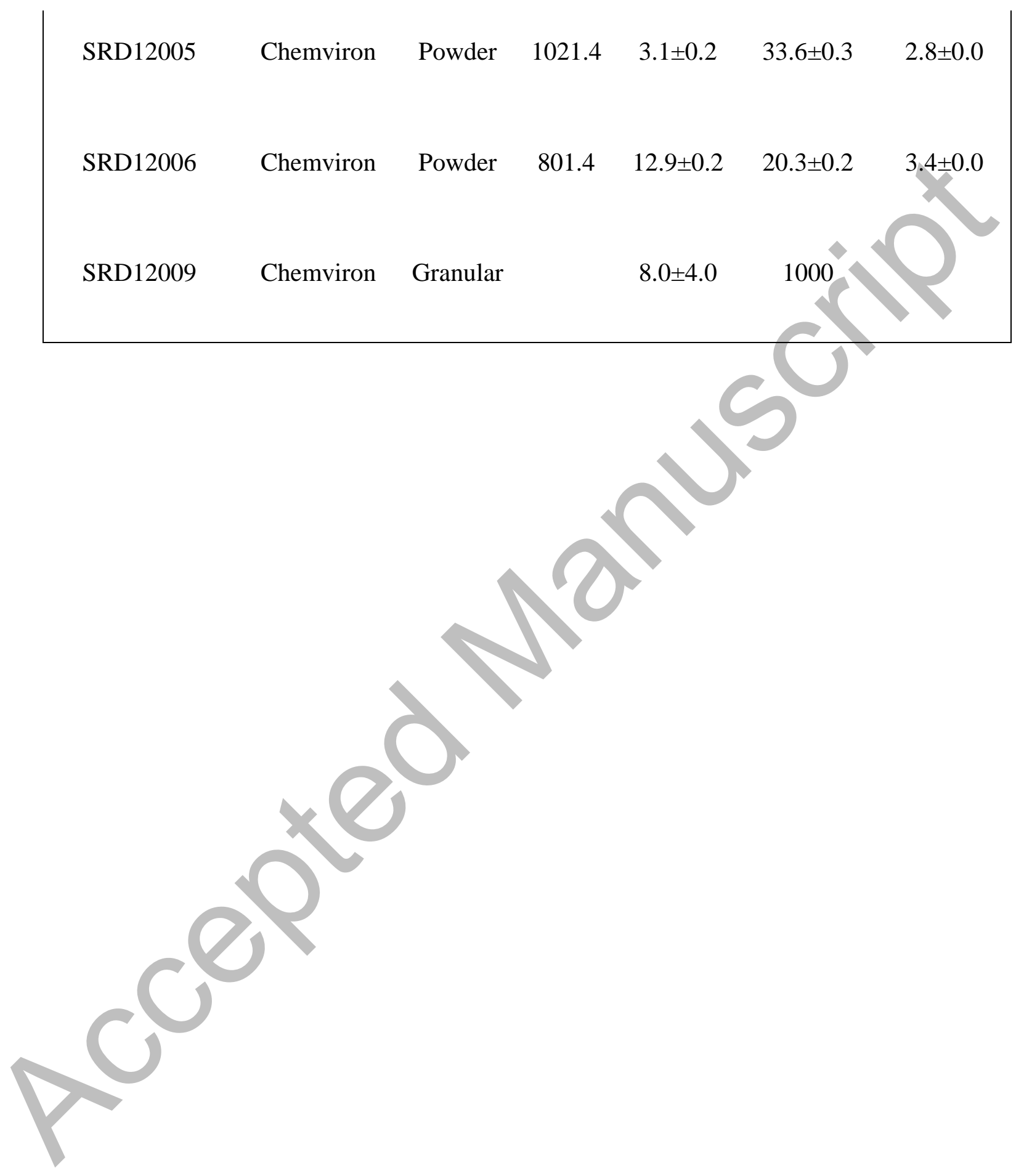


Table 2 Empirical constant of tested adsorbents

\begin{tabular}{|c|c|c|c|c|}
\hline $\begin{array}{c}\text { Adsorbent } \\
\text { samples }\end{array}$ & $\begin{array}{c}\text { Kansai coke } \\
\text { Maxsorb }\end{array}$ & $\begin{array}{l}\text { Chemviron } \\
\text { SRD12005 }\end{array}$ & $\begin{array}{c}\text { Eurocarb } \\
\text { HDLC }\end{array}$ & Eurocarb \\
\hline$x_{\max }[\mathrm{kg} / \mathrm{kg}]$ & 1.12934 & 0.512656 & 0.523924 & 0.436888 \\
\hline$E[\mathrm{~J} / \mathrm{mol}]$ & 7430 & 9348.82 & & 9466.6 \\
\hline$m$ & 2.31691 & 4 & & 4 \\
\hline$k_{0}[1 / \mathrm{s}]$ & 7175.344 & 2665157.586 & 6962213.303 & 189423.911 \\
\hline$E a[\mathrm{~J} / \mathrm{mol}]$ & 40276.718 & 54092.408 & 56203.458 & 47830.103 \\
\hline
\end{tabular}


Table 3 Physical input parameters in Comsol Multiphysics

\begin{tabular}{|c|c|c|}
\hline Physical parameter & symbol & value[units] \\
\hline Solid carbon density & $\rho_{s}$ & $2000\left[\mathrm{~kg} / \mathrm{m}^{3}\right]$ \\
\hline Packing density & $\rho_{b}$ & $300\left[\mathrm{~kg} / \mathrm{m}^{3}\right]$ \\
\hline Solid carbon conductivity & $\lambda_{s}$ & \\
\hline Initial Bed temperature & & \\
\hline Evaporating Pressure & & 3.93 and 5.232 [mbar] \\
\hline Cooling water flow & & $1[\mathrm{~m} / \mathrm{s}]$ \\
\hline Heat of adsorption & $\Delta H$ & $1053.89[\mathrm{~kJ} / \mathrm{kg}]$ \\
\hline Cooling water inlet Temp & $T_{w, i n}$ & $25\left[{ }^{\circ} \mathrm{C}\right]$ \\
\hline Metal layer thickness & $t_{\text {metal }}$ & $0.6[\mathrm{~mm}]$ \\
\hline
\end{tabular}


Figure1 SEM of tested activated carbon adsorbents
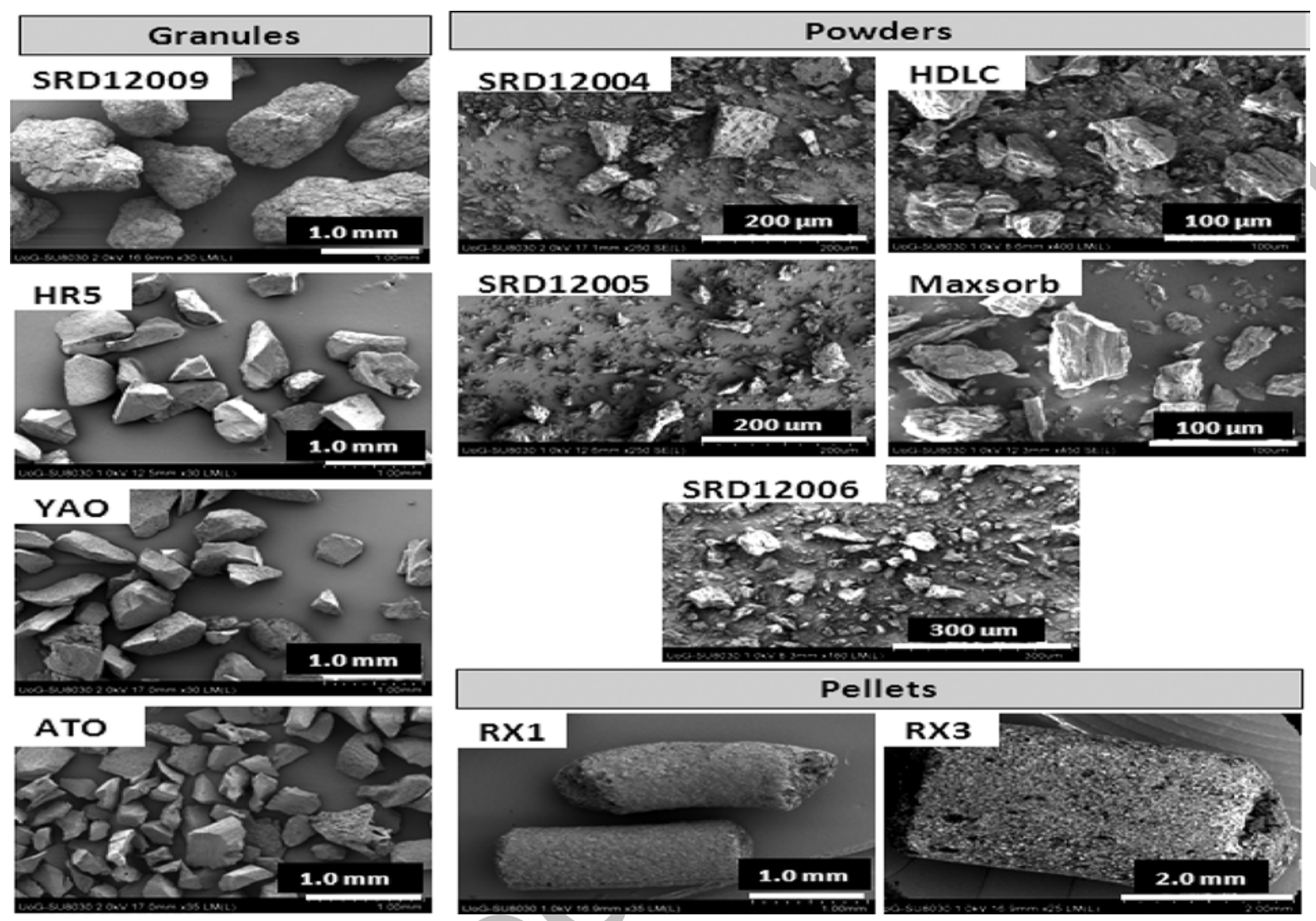

$2.0 \mathrm{~mm}$ 
Figure 2 Schematic DVS adsorption analyzer

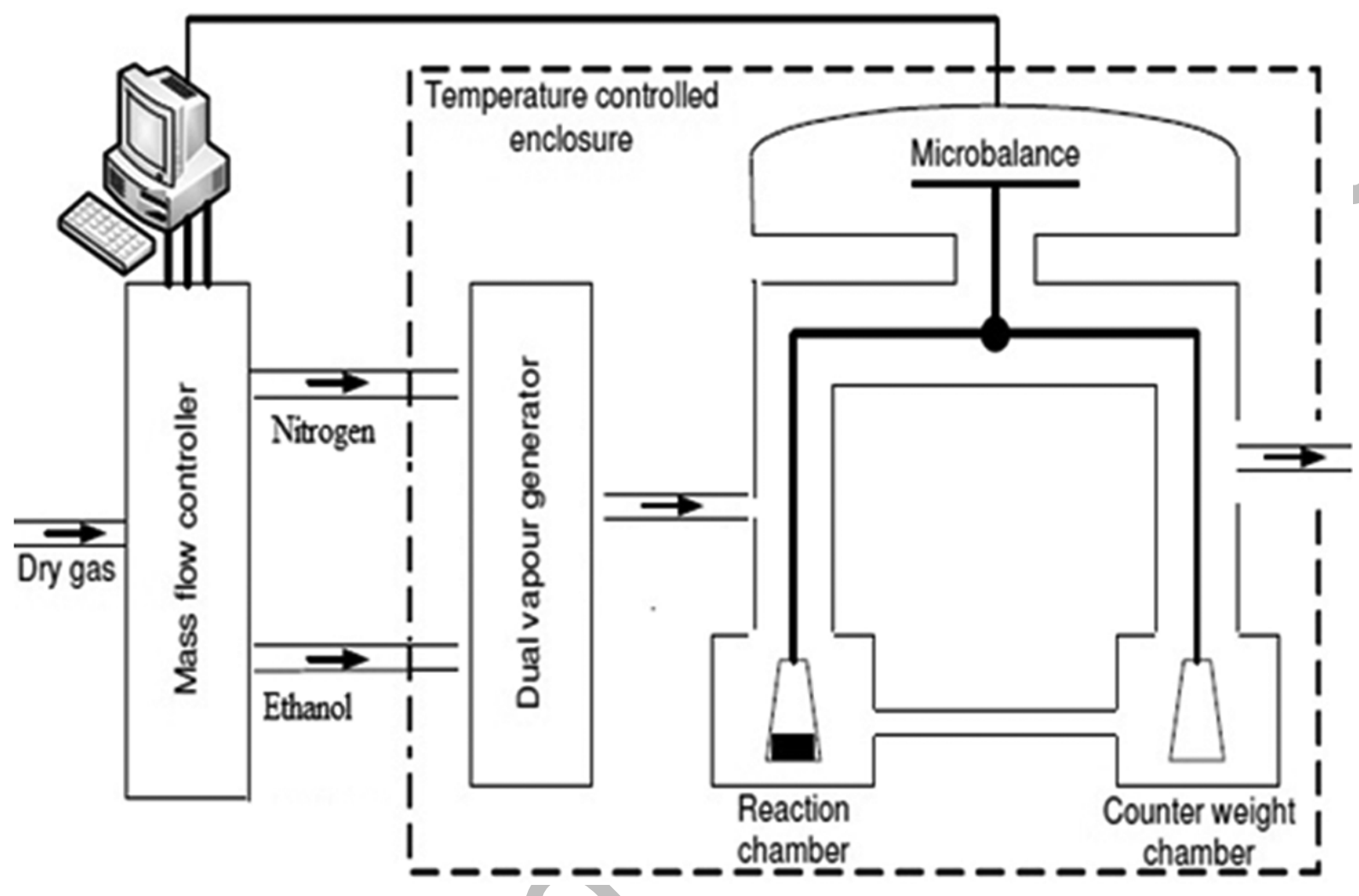


Figure 3 Comparing different samples uptake.

Figure 3a Kinetics comparisons between different samples

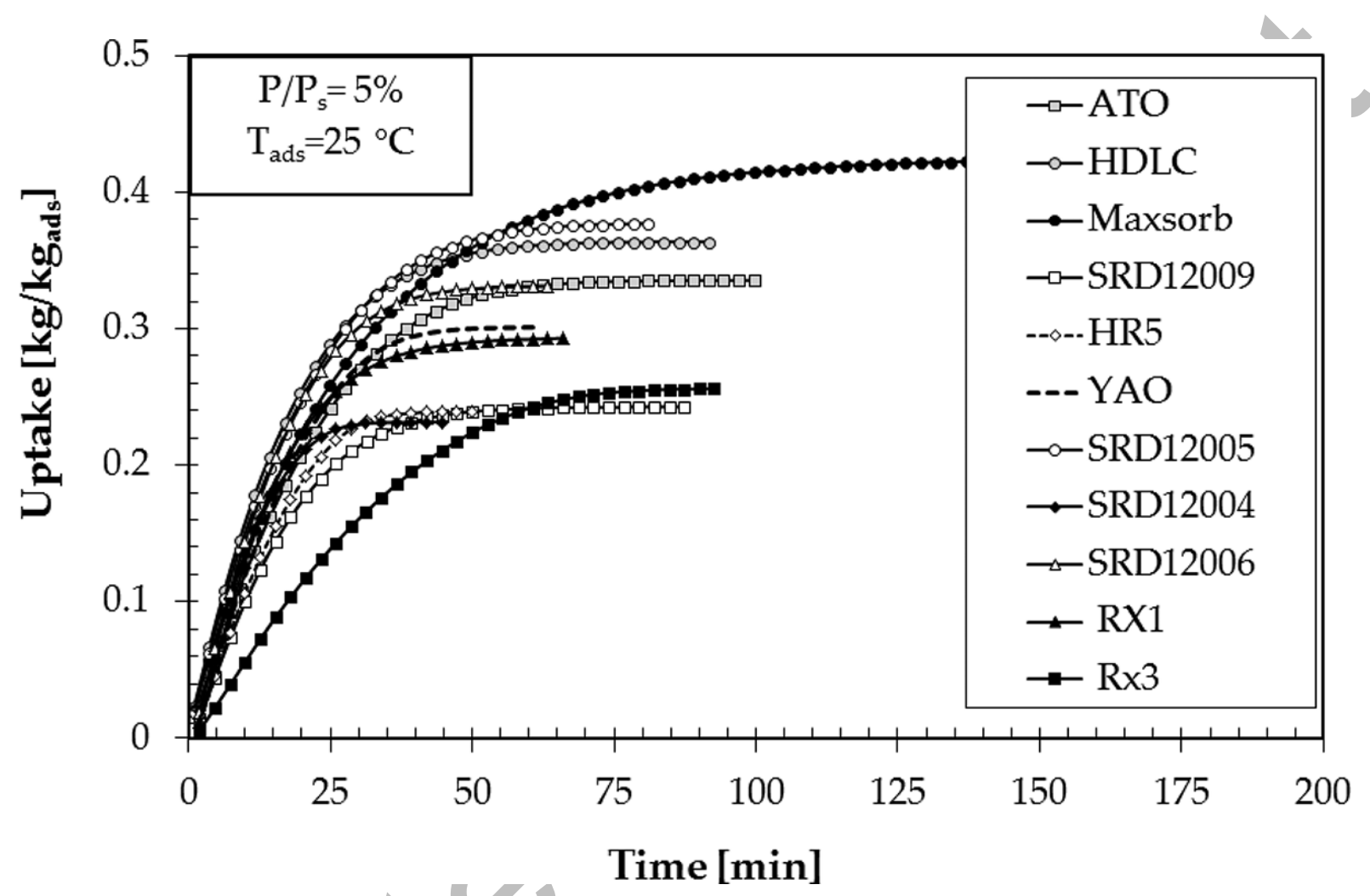


Figure 3b Ethanol Uptake at $\mathrm{P} / \mathrm{P}_{\mathrm{S}}=0.9\left(\right.$ Tads $\left.=25^{\circ} \mathrm{C}\right)$

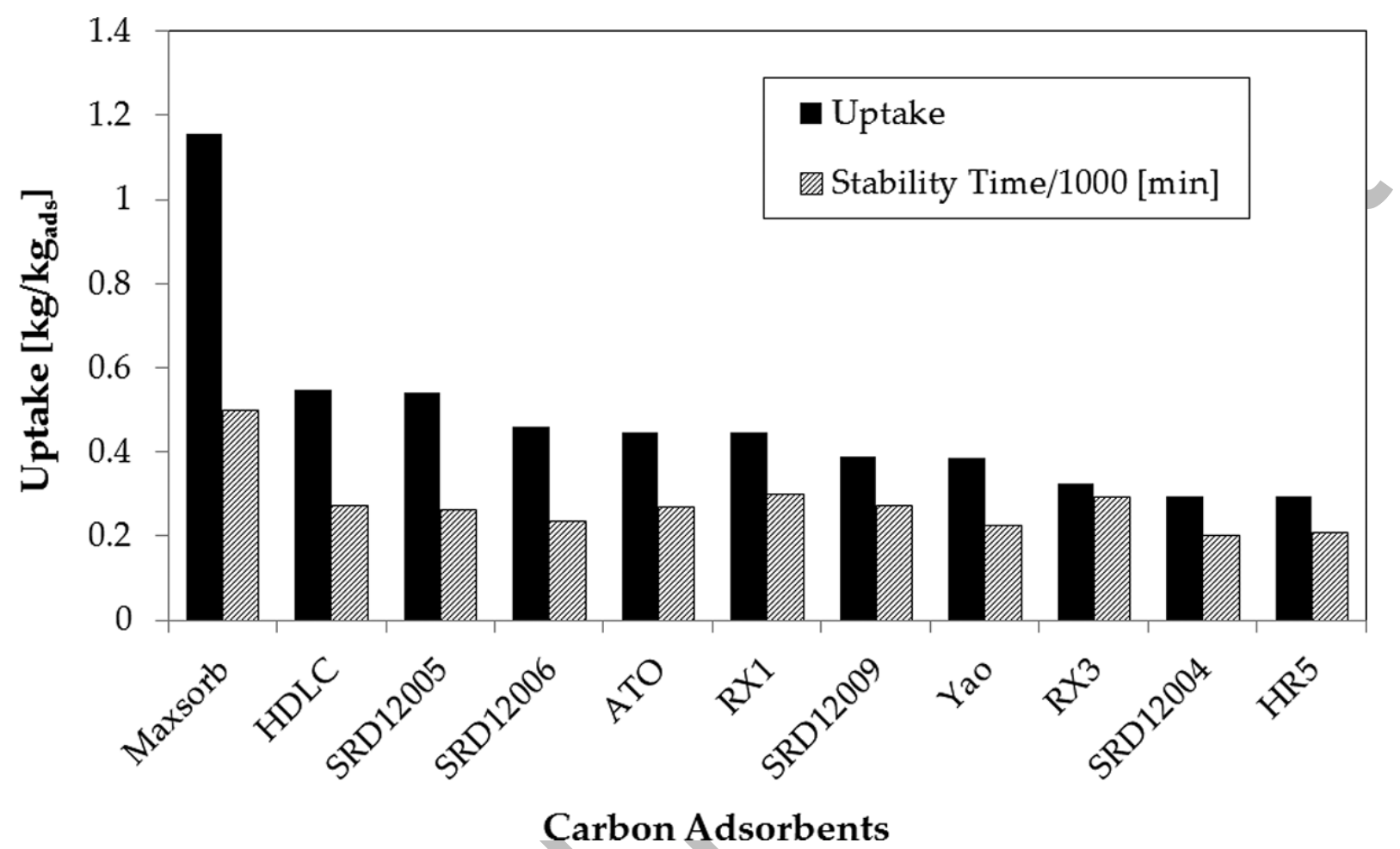


Figure 4a Prediction of adsorbent kinetics for Maxsorb

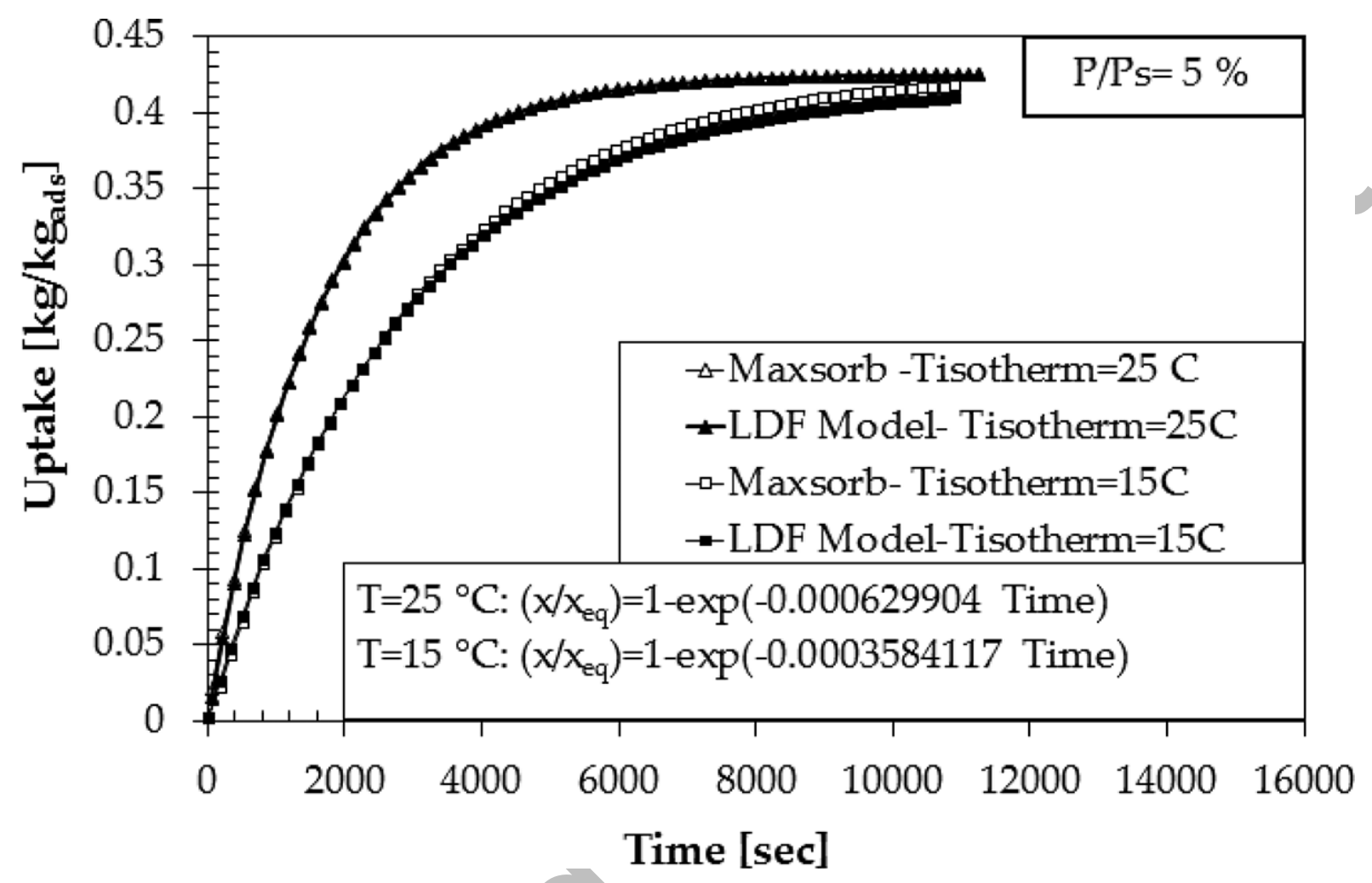


Figure 4b Maxsorb Adsorption isotherm prediction

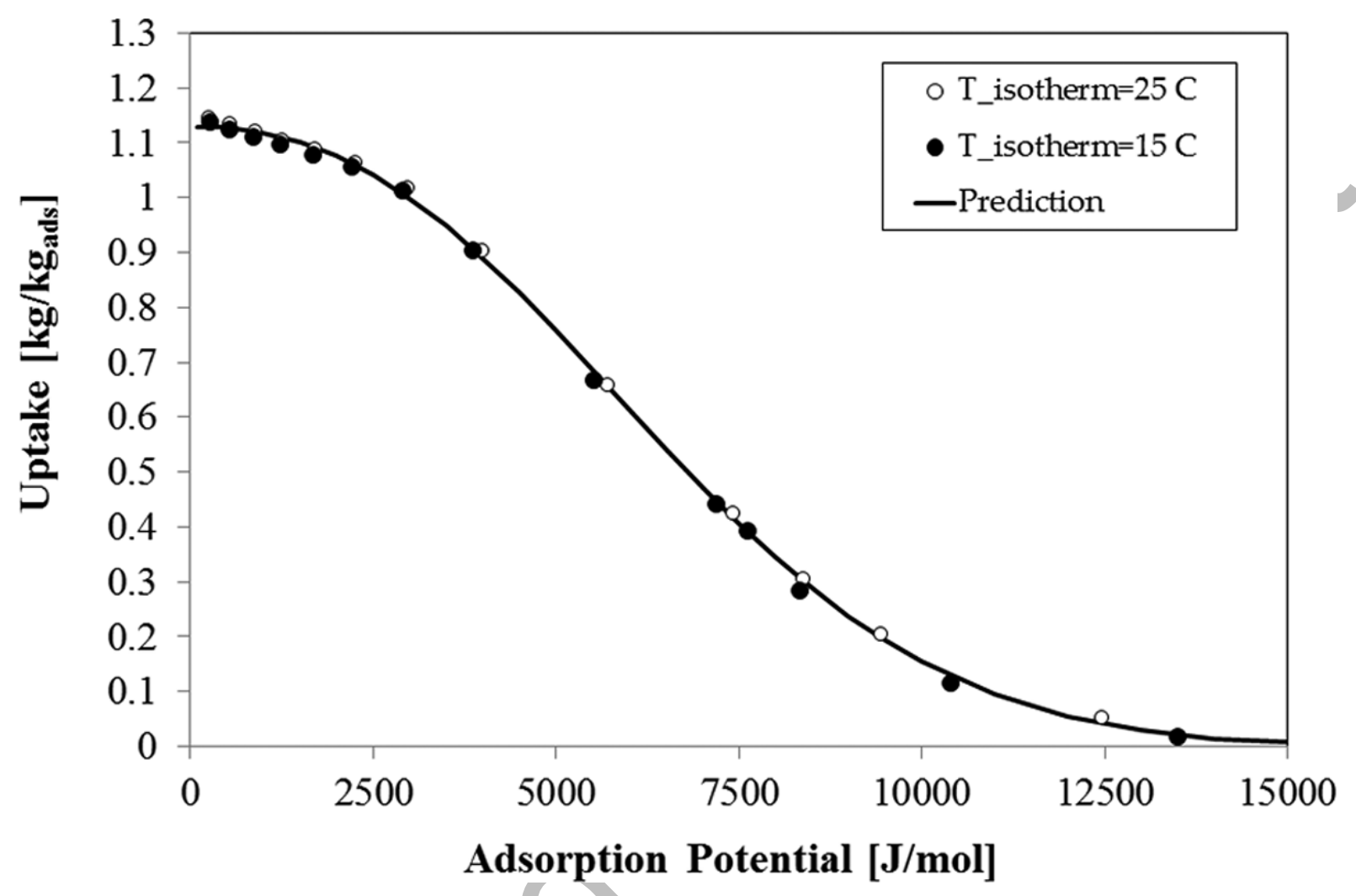


Figure 5 Plate type adsorber configuration for the CFD modeling

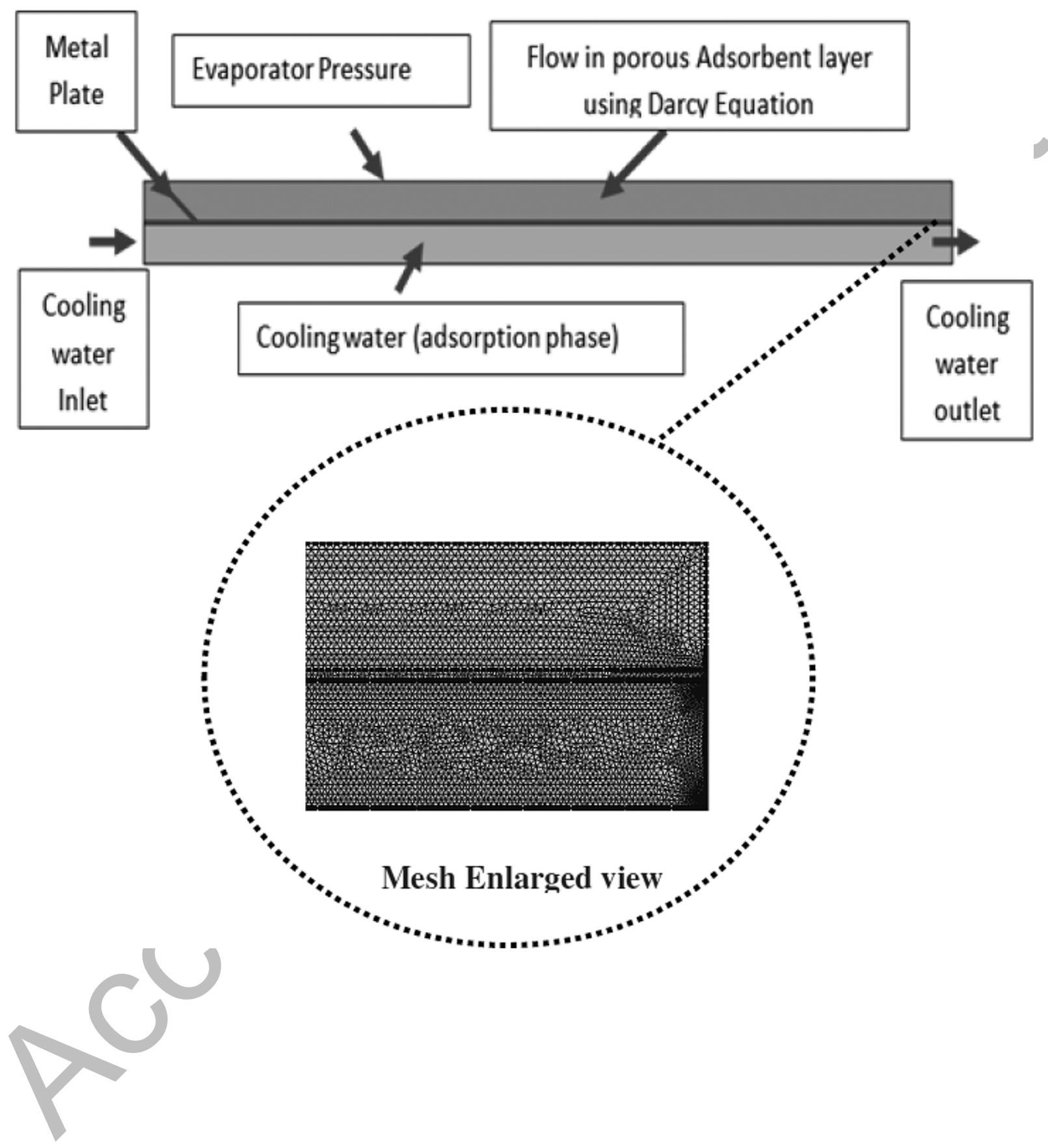


Figure 6 Maxsorb adsorbent temperature and uptake in adsorbent layer after 180 sec

(a)
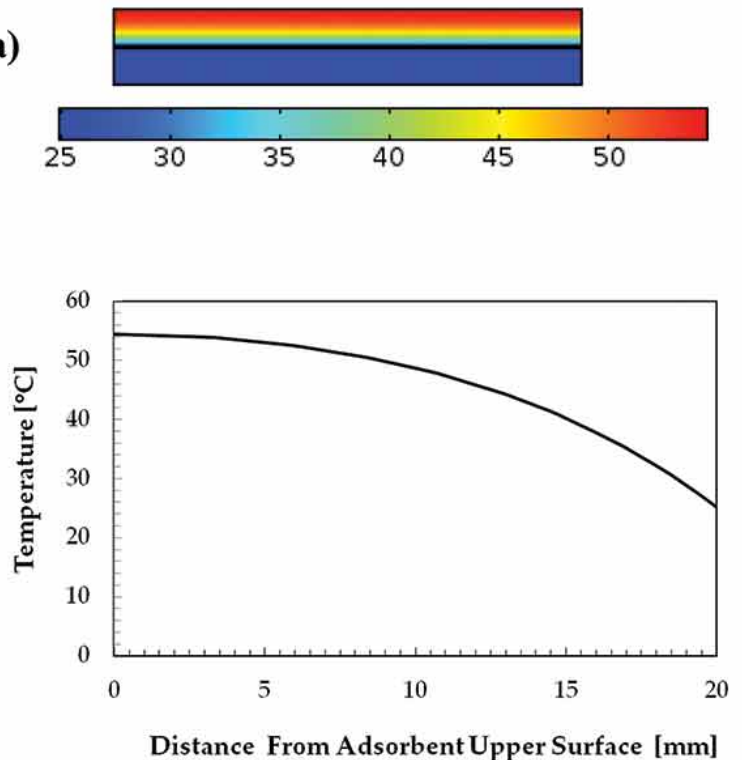

(b)
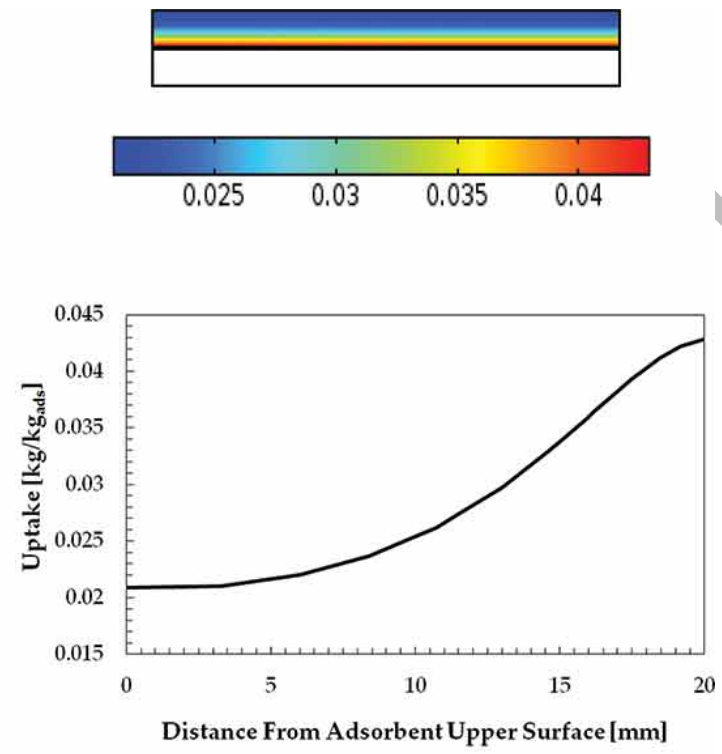
Figure 7 CFD Model validation

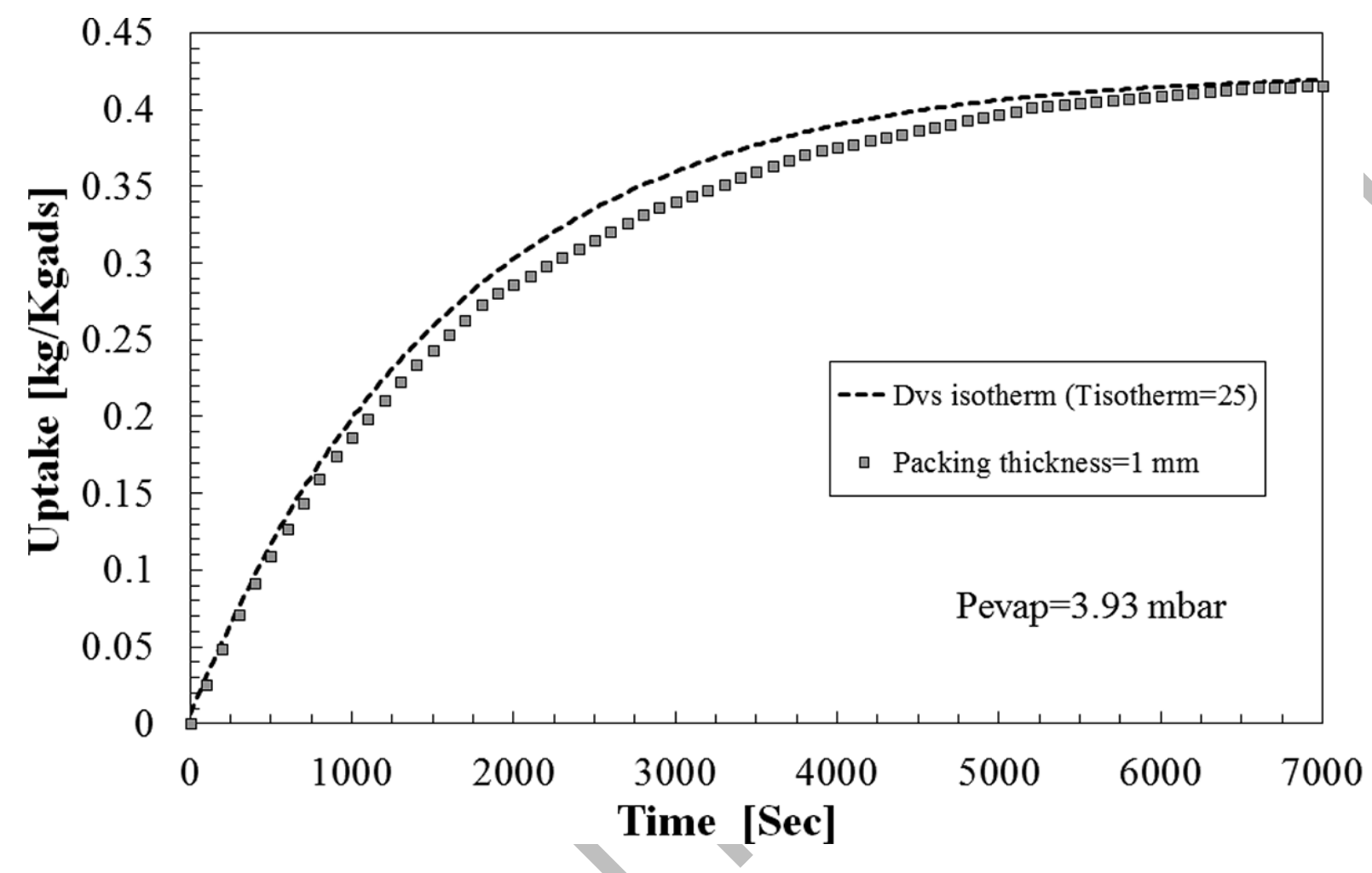


Figure 8 Performance of dry bed with packing thickness

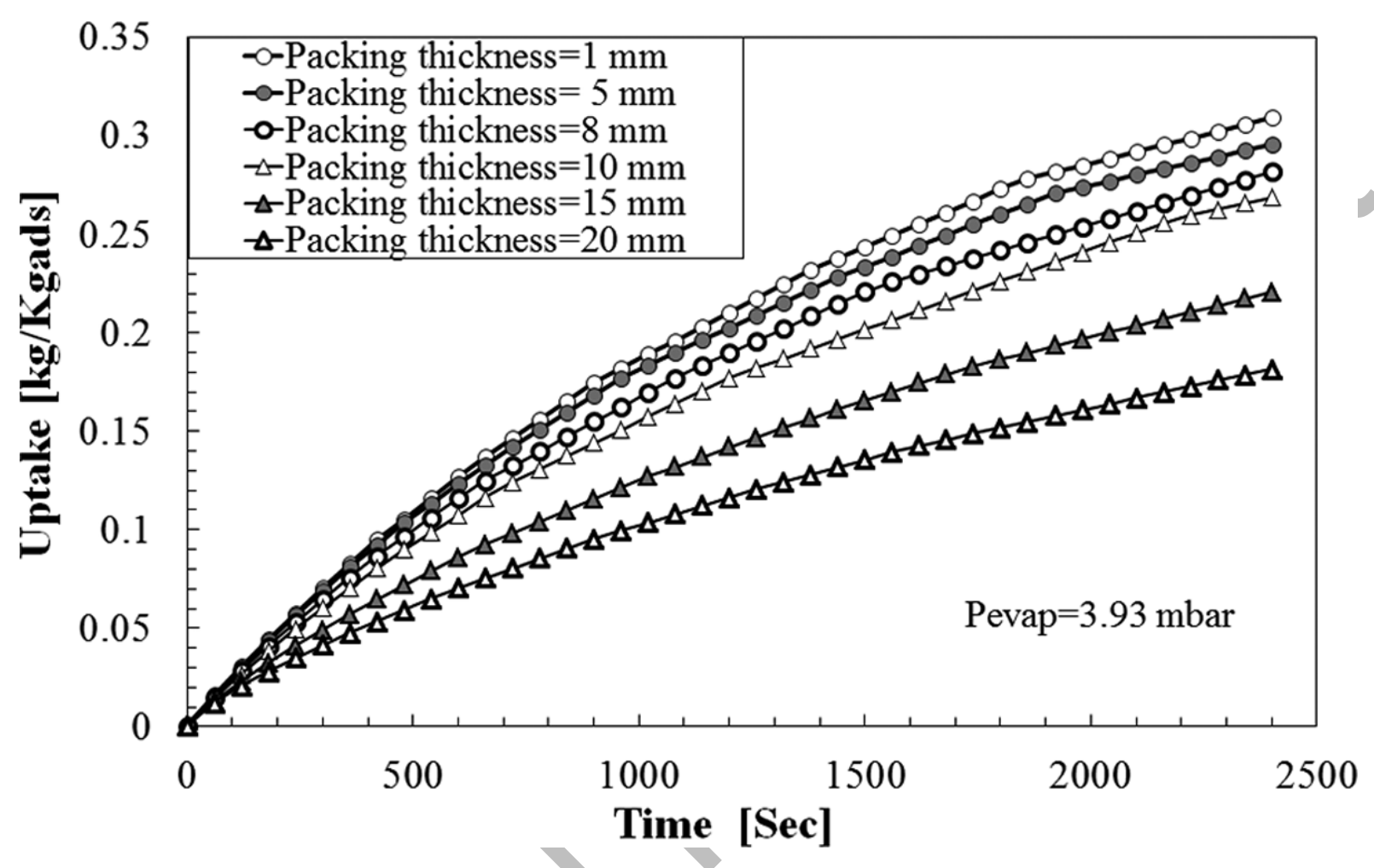


Figure 9 Transient average bed temperature of dry bed

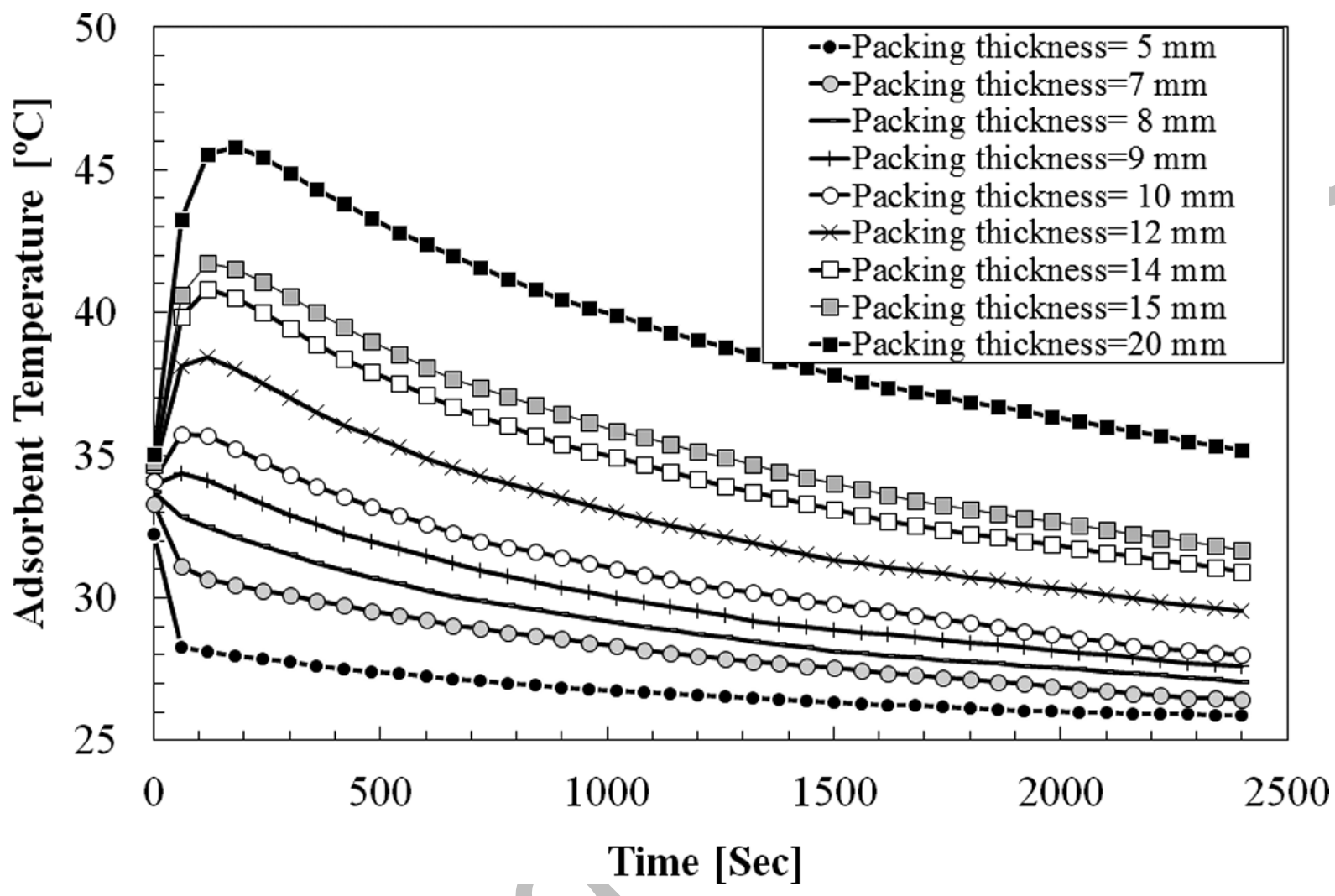


Figure 10 Chiller SCP at various adsorbent thicknesses

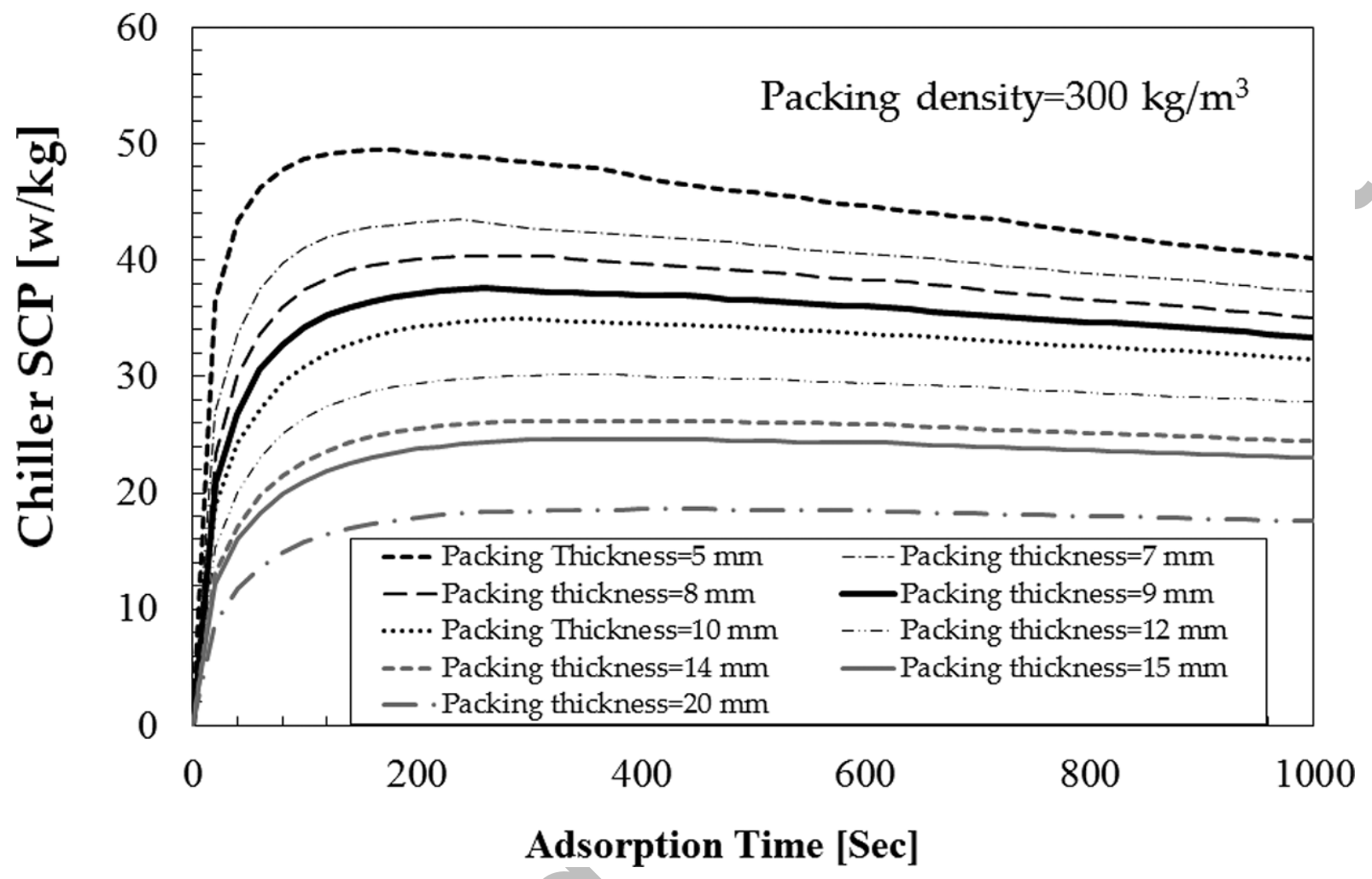


Figure 11 Effect of packing density on bed porosity and thermal conductivity

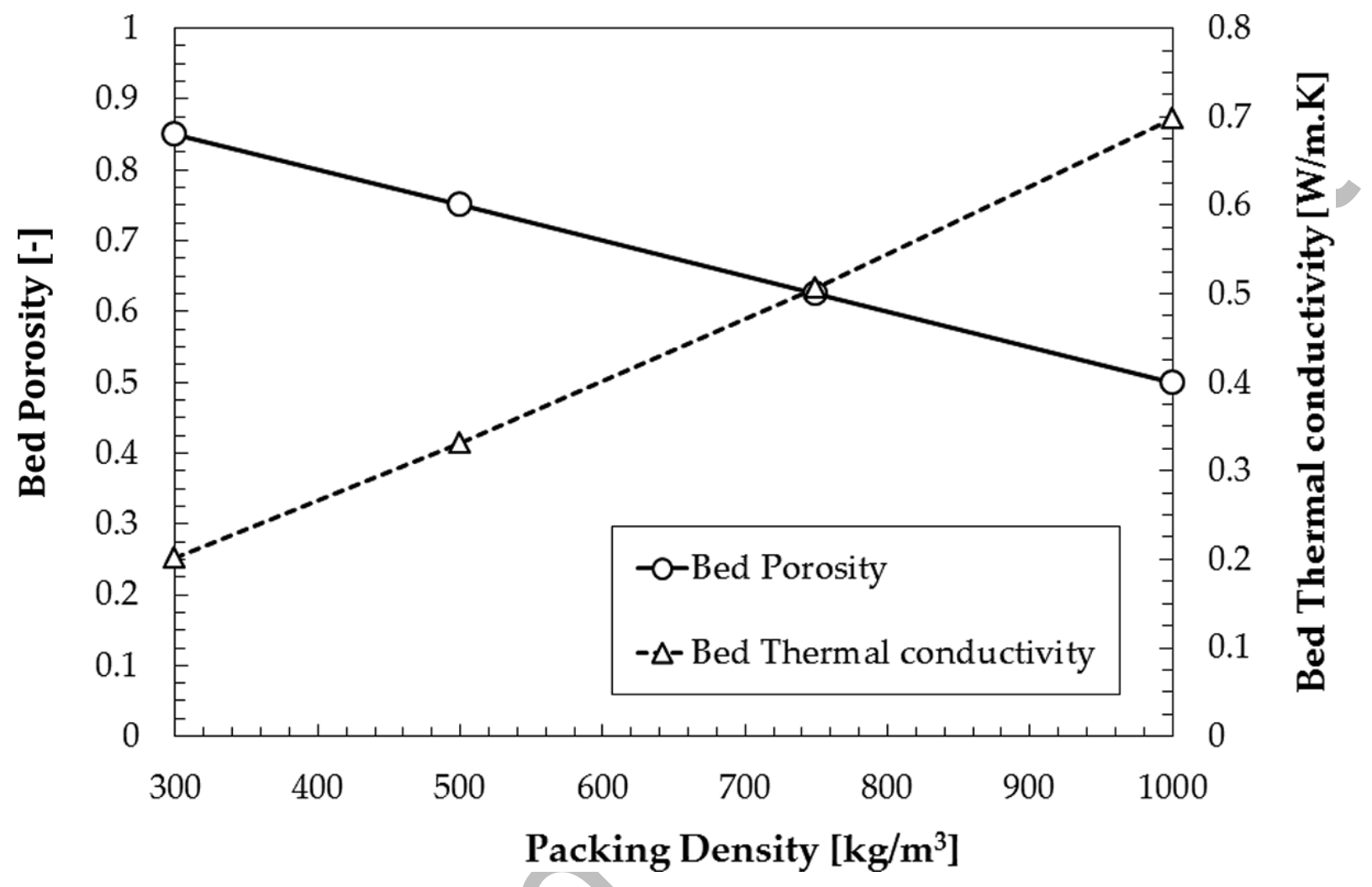


Figure 12 Effect of packing density on the adsorbed ethanol per plate

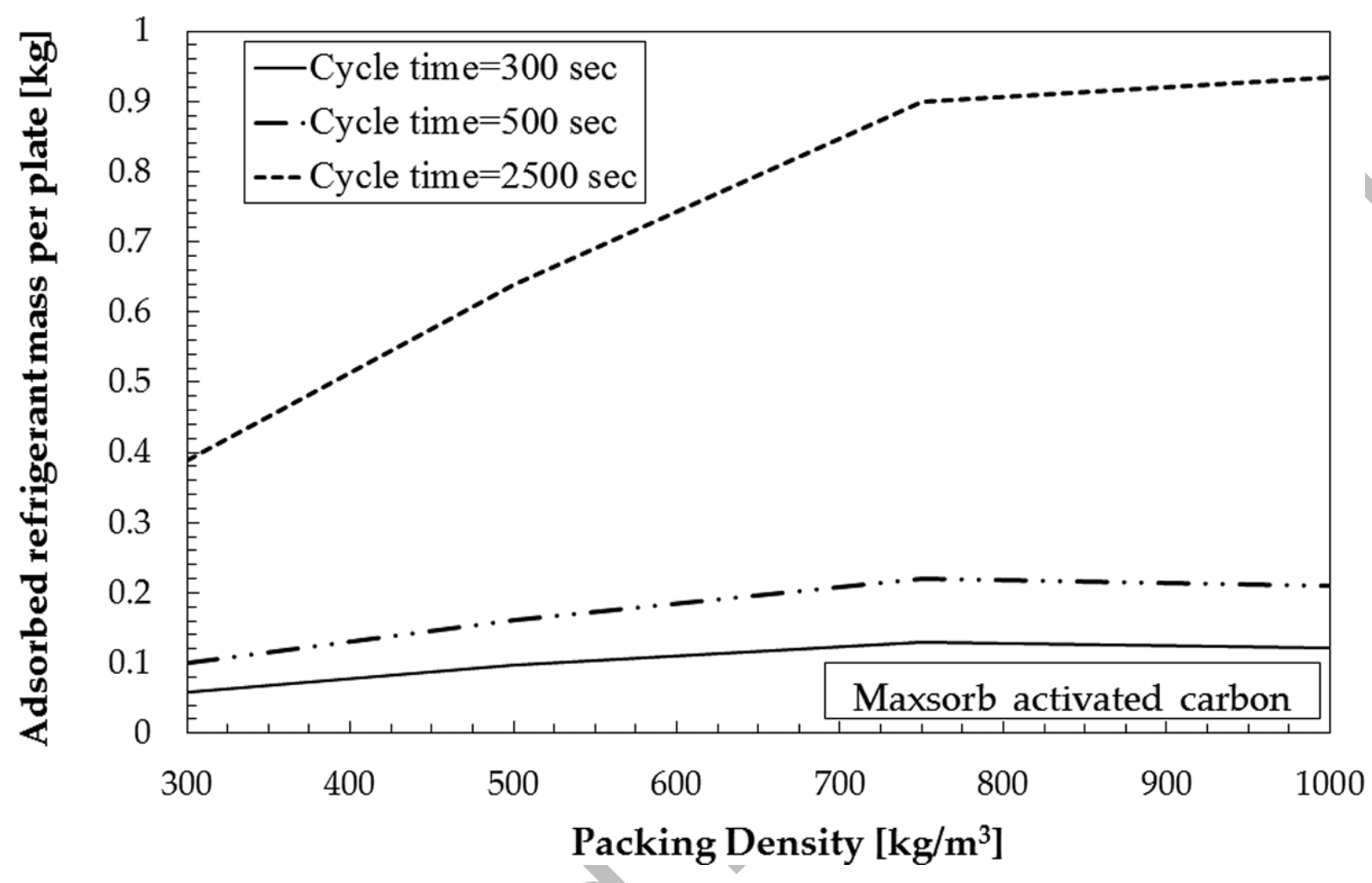


Figure 13: Comparing maxsorb/ethanol pair with different low temperature pairs

Figure 13a Comparing different cycle uptake for low temperature working pairs

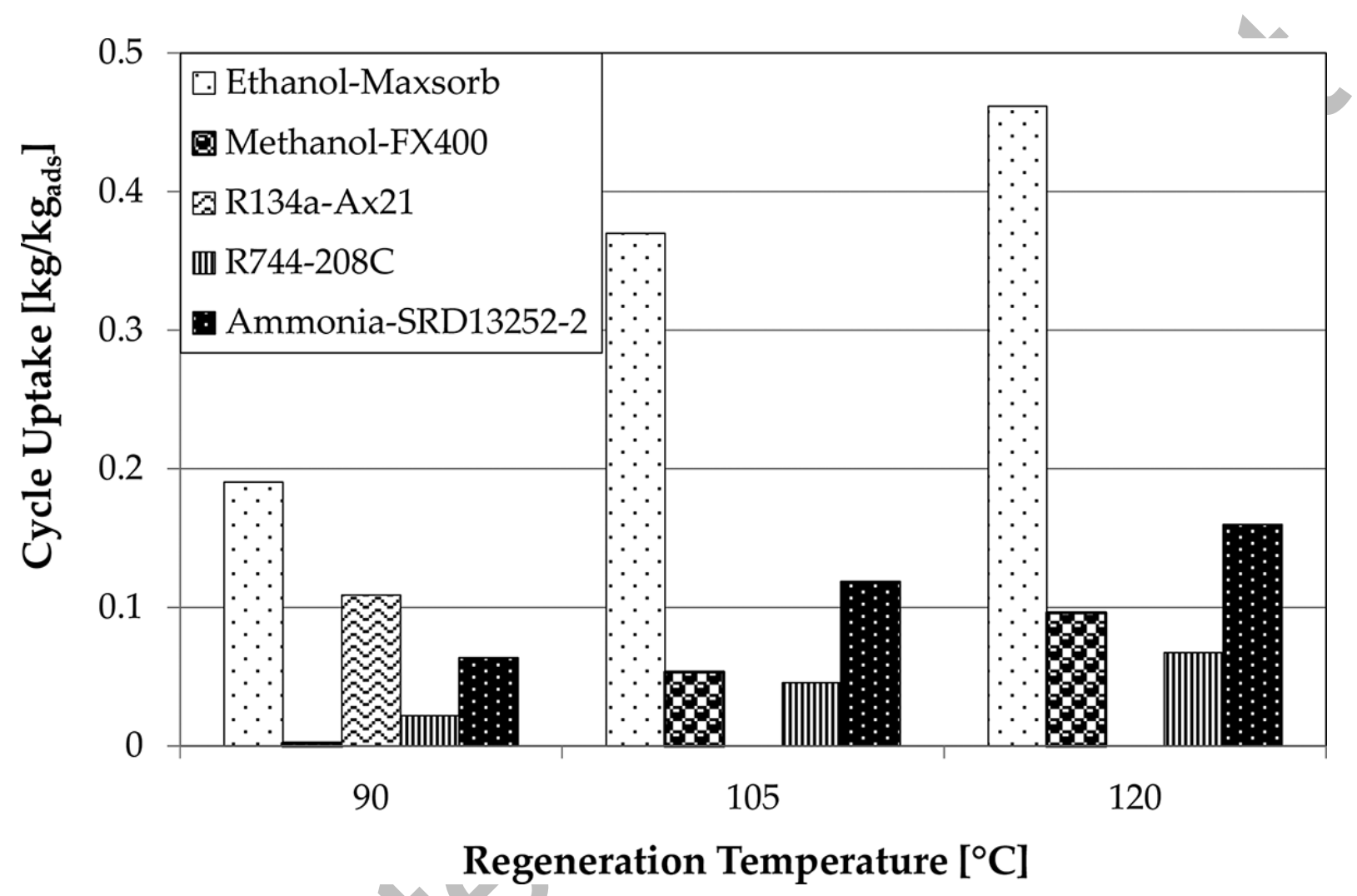


Figure 13b Comparing different SCE for low temperature working pairs

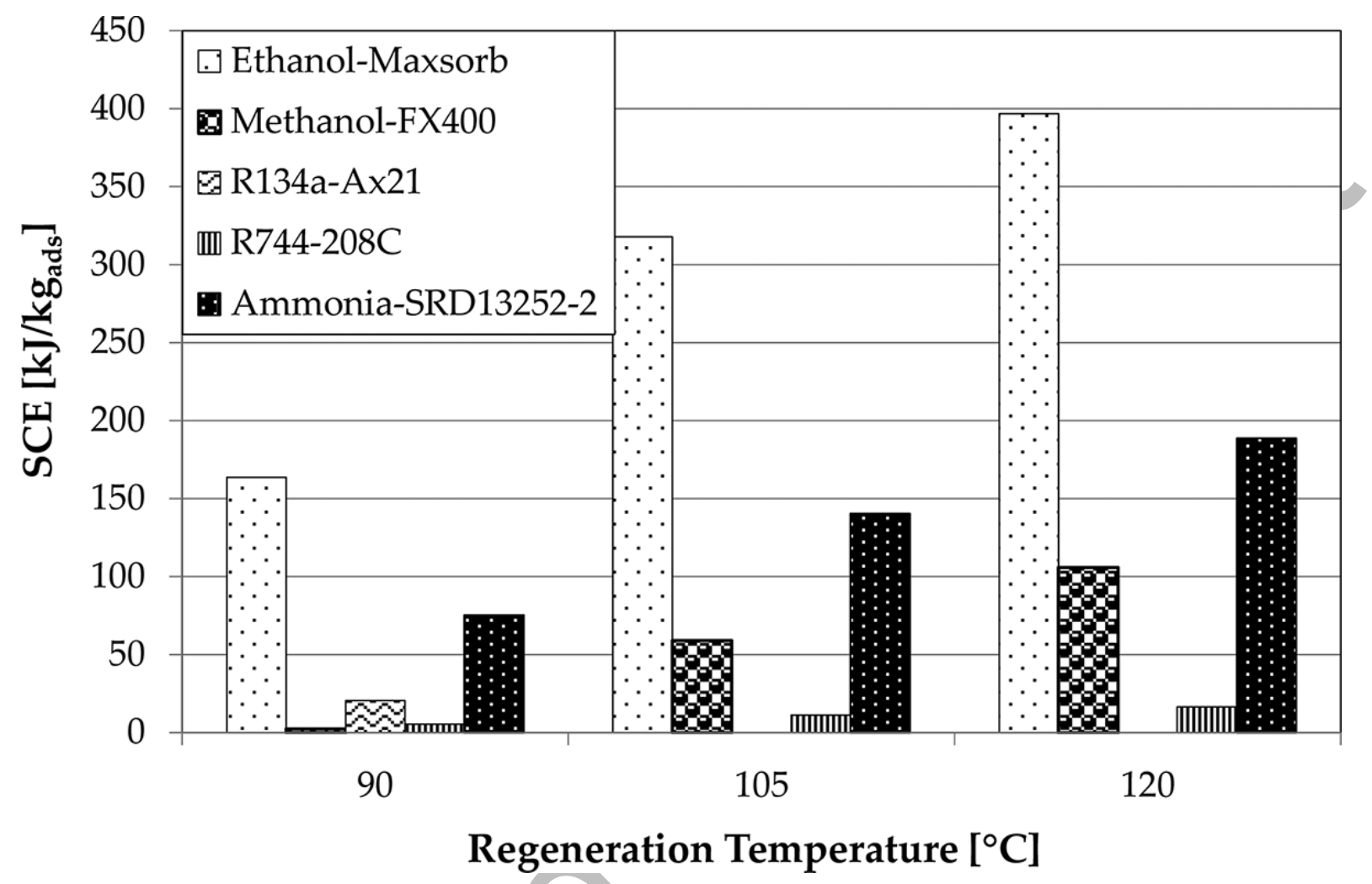

